\title{
Representações literárias do processo de descolonização em Angola e Moçambique
}

\author{
Donizeth Santos ${ }^{1}$
}

RESUMO: O artigo apresenta uma análise do modo como escritores portugueses e africanos de língua portuguesa representaram em seus romances o processo de descolonização ocorrido na década de 70 nas ex-colônias portuguesas de Angola e Moçambique. O corpus do trabalho é constituído pelas obras: Yaka (1984), do angolano Pepetela; Vinte zinco (2004), do moçambicano Mia Couto; e O esplendor de Portugal (1999) e Os cus de Judas (1999), do português António Lobo Antunes.

ABSTRACT: The article presents an analysis about the way of Portuguese and African writers of Portuguese language had represented in its romances the process of descolonization occurred in the 70's in Angola and Mozambique, Portuguese ex-colonies in Africa. The corpus of the work is formed by: Yaka (1984), of the Angolan Pepetela; Vinte zinco (2004), of the Mozambican Mia Couto; and $O$ esplendor de Portugal (1999) and Os cus de Judas (1999), from the Portuguese António Lobo Antunes.

PALAVRAS-CHAVE: Literatura comparada; Literatura portuguesa, Literaturas africanas de língua portuguesa.

KEYWORDS: Comparative literature; Portuguese literature; African literature of Portuguese language

\author{
Chuva novembrina \\ Chuva-chuva doce chuva \\ entra no meu coração \\ doce chuva solitária \\ Contigo eu remanso a noite \\ desce a noite e desces tu \\ doce chuva mãos de mulher \\ afagado o bolor do sofrimento \\ Vem doce teta de chuva. \\ (José Luís Mendonça)
}

Utilizamos como epígrafe os versos do poeta angolano José Luís Mendonça para iniciar este artigo sobre as "representações literárias do processo de descolonização em Angola e Moçambique" porque pensamos que eles tocam em duas das maiores metáforas empregadas pelos escritores africanos de língua portuguesa para caracterizar

\footnotetext{
${ }^{1}$ Doutorando da Universidade de São Paulo.
} 
o processo colonial português em terras africanas: a noite, metáfora da opressão colonial, e a chuva, metáfora da descolonização.

E antes de abordarmos diretamente o processo de descolonização ocorrido em Angola e Moçambique, representado literariamente nas obras Yaka (1984), do angolano Pepetela; Vinte zinco (2004), do moçambicano Mia Couto; Os cus de Judas (2003) e $O$ esplendor de Portugal (1999), do português António Lobo Antunes, é necessário lembrar outro significativo poema angolano, o profético "Aqui no cárcere", escrito na década de 60 pelo poeta e ex-presidente angolano Agostinho Neto, no qual o sujeito poético afirma que ninguém seria capaz de impedir a chuva, ou seja, que nada poderia deter a independência de Angola:

Aqui no cárcere, a raiva contida no peito, espero pacientemente o acumular das nuvens ao sopro da história: ninguém impedirá a chuva (NETO, 1984, p. 35)

Em Yaka (1984), romance que aborda os fatos históricos da colonização portuguesa no centro-sul de Angola, desde 1890 até os meses que precederam a independência angolana em 1975, e que tem como fio condutor a história da família Semedo, colonos portugueses vindos para a colônia no final do século XIX, traz o prenúncio da descolonização e da independência angolana metaforizados na chuva. $\mathrm{Na}$ última parte do romance de Pepetela, intitulada "As pernas", os chuviscos e orvalhos que metaforizam as primeiras revoltas anticoloniais se transformam numa chuva torrencial que cai sobre o território angolano, trazendo com ela a certeza do fecundar de uma pátria angolana, consumando, dessa forma, a previsão de Agostinho Neto de que nada poderia impedir que, ao longo do tempo, as nuvens se acumulassem e formassem uma grande chuva, a doce chuva novembrina de José Luis Mendonça, que remansaria a terrível noite colonial e traria a independência angolana:

Foram os orvalhos e chuviscos primeiros, depois as chuvas dispersas por Cabinda e o imenso Leste então, quando tudo estava quieto ao sol e até o lagarto azul tinha preguiça de os dizer sim-sim, com a cabeça pesada de meio-dia, quando os siripis se encolhiam debaixo das folhas procurando sombra, quando a paz mentirosa parecia enlanguescer os músculos e as vontades, estourou aquele trovão medonho que para muitos era música de marimba anunciando água fresquinha a cair gota a gota de cascatas intermináveis ou era cadência frenética de mbulumbumba a despertar os homens e o gado, e para outros foi só isso mesmo, um trovão medonho de estarrecer, como Bartolomeu 
Espinha que gritou esses capitães já me foderam, traidores da merda, a brincarem aos golpes de Estado, e o rádio que repetia não se sabe bem o sucedido em Lisboa, mas já o trovão tinha chamado as nuvens grossas e os batuques refloresceram nos cânticos coletivos de bater palmas, agora é que era, e as armas lá na mata dispararam saraivadas para o ar festejando a vitória coletiva e ninguém que segurava mais o processo pois não tinha mais quem quisesse lutar para travar o avanço impetuoso das nuvens e as faíscas brilhavam nas noites e o batuque aumentava e os cantos aumentavam e as nuvens vinham e eu danço por cima do Pundo, da Chela, das Mundas, do Moco, do Mucaba e das chanas orientais, chuva diferente caindo que não provocava enxurradas na terra sequiosa, só abria os sorrisos e a música das flores silvestres... (PEPETELA, 1984, p.244)

O "trovão medonho" referido por Pepetela, uma metáfora da Revolução dos Cravos, que anunciou a chegada da chuva (a independência política), trazendo alegria para muitos (os angolanos) e medo para outros (colonos portugueses exploradores da terra angolana) é utilizado também por Mia Couto em Vinte zinco (2004) com o mesmo sentido metafórico:

E o céu também em suas visões, se apocalipsa. Como se de uma imensa almofada irrompesse um infinito algodão, capaz de encher os horizontes. E essa branquidão, em propulsões, se espalha, afogando o azul-celeste. Começa a trovejar. As gentes, encolhidas, já misturam choros e preces. Trovejar assim em abril? Os poderes dos deuses falavam pelos desnorteados olhos de Tchuvisco?

I.....

... É trovoada, grossa e cheia. Parece, em volta, as nuvens e entre nuvens se roseiam. No meio de tais figurações, Lourenço dá por si gritando:

- Chamem o padre Ramos!

Mas é tarde. Num instante, o céu se inviabiliza para pássaros, a terra se fecha para encantações. Chove em toda a vastidão do mundo.

(COUTO, 2004, p. 63-65)

Nessa obra estruturada em forma de diário, o autor retrata os últimos dias do mês de abril (de 19 a 30) de 1974 em Moçambique. Os protagonistas são o agente da PIDE Lourenço de Castro, uma sinédoque do poder colonial que se dissolve nas colônias após o 25 de abril, e o pintor cego moçambicano Andaré Tchuvisco, uma vítima do sistema que tinha a função de apagar as marcas de sangue dos torturados nas paredes das prisões coloniais. Ambos representam o contraste entre o colonizador e o colonizado na colônia.

Essa mesma chuva que nos romances africanos representa alegria, transformação e renascimento, como metáfora das independências políticas das colônias portuguesas 
em África, surge nos romances O esplendor de Portugal (1999) e Os cus de Judas (2003), do português António Lobo Antunes, ligada à ideia de tristeza e de morte.

O primeiro romance, $O$ esplendor de Portugal, tem como protagonistas uma família de colonos portugueses estabelecidos em Angola, e retrata o caos vivido por seus integrantes no período da descolonização; e o segundo, Os cus de Judas, é o relato nu e cru da guerra colonial em Angola, sob o ponto de vista de um médico português que se vê obrigado a se juntar às tropas portuguesas quatro meses depois de se casar. Nesse aspecto, é muito significativa a reflexão do médico (soldado) português quando obtém uma breve licença para conhecer a filha recém-nascida em Lisboa:

.... a regressar da guerra de África para conhecer a filha, numa dessas madrugadas de Novembro tristes como chuva num pátio de colégio, durante a lição de Matemática. (ANTUNES, 2003, p.98)

Aqui não se pode esquecer que a independência angolana metaforizada em chuva nos romances africanos ocorreu em 11 de novembro, o mesmo mês em que o personagem de Lobo Antunes associa a chuva à tristeza.

A colona portuguesa Isilda de $O$ esplendor de Portugal (1999), que permanece em Angola depois da independência, associa a chuva à morte de seus familiares. Como esses familiares possuíam uma posição hierárquica superior à sua: o pai, a mãe, e o marido, pode-se estabelecer uma relação sinedoquica /metafórica entre essas mortes e o fim do regime colonial português:

... o enterro do meu pai sob a chuva, o enterro da minha mãe sob a chuva, o enterro do meu marido sob a chuva, todos os meus enterros sob a chuva, a água a descolorir as flores molhadas, a cal a ferver na madeira.... (ANTUNES, 1999, p.294)

Outra relação sinedoquica /metafórica que se pode estabelecer entre a associação da chuva à morte de portugueses e à morte do regime colonial está em Os cus de Judas (2003), através da reflexão do narrador-personagem durante uma operação de guerra:

Descíamos do Luso para as Terras do Fim do Mundo, em coluna, por picadas de areia, Lucuse, Luanguinga, as companhias independentes que protegiam a construção da estrada, o deserto uniforme e feio do Leste, quimbos cercados de arame farpado em torno dos préfabricados dos quartéis, o silêncio de cemitério dos refeitórios, casernas de zinco a apodrecer, descíamos para as Terras do Fim do Mundo, a dois mil quilômetros de Luanda, Janeiro acabava, chovia, e 
íamos morrer e chovia, chovia, sentado na cabina da camioneta, ao lado do condutor, de boné nos olhos, o vibrar de um cigarro infinito na mão, iniciei a dolorosa aprendizagem da agonia. (ANTUNES, 2003, p.43)

Dessa forma, a chuva que traz alegria e prenúncios de boas novas a angolanos e moçambicanos é associada à tristeza e à morte pelos portugueses, numa clara referência ao fim do colonialismo português, cujo golpe final foi dado pela Revolução dos Cravos, metaforizada em trovão em Yaka e Vinte zinco.

A Revolução dos Cravos ocorrida em 25 de abril de 1974 derrubou o regime autoritário do Estado Novo "com flores no cano das espingardas" (LOURENÇO, 2004, p. 49), depois de quase 50 anos de ditadura salazarista. A partir dela, a descolonização dos territórios ultramarinos tornou-se inevitável e assim os processos de descolonização, que tinham sido iniciados em Angola e Moçambique no começo da década de 60, encontram seus desfechos após mais de uma década de confrontos violentos entre os portugueses e os angolanos e moçambicanos revolucionários.

Segundo Eduardo Lourenço (2004, p.49), a Revolução dos Cravos eclodiu com o propósito de encontrar dentro da imagem de um Portugal colonizador exemplar uma solução à portuguesa, igualmente exemplar de descolonização. No entanto, o objetivo principal do processo descolonizador português, que era uma descolonização com uma presença portuguesa em África, não foi alcançado.

Pelo contrário, a descolonização que se deu após a Revolução dos Cravos provocou um verdadeiro êxodo dos colonos portugueses com destino à metrópole. De acordo com Benjamin Abdala Júnior (2003, p.135), “mais de oitocentos mil retornados ingressaram no país após anos de convivência africana”, o que corresponde, segundo o autor, a cerca de $8 \%$ da atual população portuguesa. Tanto os romances africanos quanto os portugueses aqui analisados retratam em suas páginas essa retirada em massa dos colonos dos territórios de Angola e Moçambique, como elementos históricos-sociais externos que se internalizam no texto literário, conforme a acepção de Antonio Candido (2000, p.5).

Em Yaka (1984), na noite em que sua família foge para a África do Sul, Joel ouve um tenente português, namorado de sua prima Chucha, contar-lhe sobre o caos reinante no porto do Lobito, onde já não havia espaço para abrigar as levas de colonos que chegavam a todo momento, carregados com seus pertences, tentando embarcar para Portugal. Desconhecendo a gravidade dos crimes cometidos por alguns de seus parentes 
no período colonial, Joel não compreende o porquê da paranóia deles, assim como dos demais colonos, em querer fugir.

- Então explique-me por que querem bazar todos - disse Joel.

O tenente brincou com o copo de uísque.

Têm medo. De tudo. Sobretudo do passado.

- Os que fizeram crimes, está bem disse Joel - Mas o meu pai de que pode ter medo? Sempre foi um desgraçado. Nem sei como vai viver lá fora, não sabe fazer nada...

- Aí o caso pode ser diferente. Mesmo sem saber fazer nada, como dizes, aqui tinha o emprego. Era superior aos negros, tinha o estatuto de branco. Sabe que vai perder esse estatuto. A partir de agora será igual a eles, não terá privilégios. Tem de mostrar o que sabe fazer. É duro para quem toda vida viveu pensando ter inferiores. De repente já não os tem. É igual a eles...

- Mas lá vai ser inferior a todos!

- A todos os que ele considera seus iguais. Não pode aceitar o risco de ser inferior aos que ele toda a vida considerou inferiores...

É muito complicado tudo isto. (PEPETELA, 1984, p.288)

Nesse novo ciclo da história angolana que se desenha só há lugar para portugueses e descendentes que se tornarem angolanos, ou seja, para aqueles que aceitarem a nova condição social em que estarão no mesmo nível dos angolanos nativos, destituídos dos princípios de superioridade de raça e classe que o regime colonial lhes outorgava.

Por isso, os únicos integrantes da família Semedo que se dispõem a ficar são o patriarca Alexandre Semedo, que sofre um longo e lento processo de angolanização, e seu bisneto Joel, que se engaja nas forças do Movimento Popular de Libertação de Angola (MPLA). Os demais membros, a exemplos de muitos outros portugueses e descendentes, preocupados com situações econômicas, políticas e sociais, só veem saída na fuga para a África do Sul ou Portugal.

Em Vinte zinco, após o 25 de abril, a menção a fuga é uma constante. No mesmo dia da Revolução dos Cravos a mãe de Lourenço de Castro tenta convencê-lo a ir embora:

- A única coisa que eu quero é ir embora. Todos esses anos, esse foi o meu sonho. E agora, Lourenço de Castro, só nos resta mesmo é ir embora.

/.../

Quando o teu pai morreu eu pensei que tudo tinha acabado. E que voltávamos para nossa aldeia, de onde nunca devíamos ter saído. Mas depois tu quiseste-o vingar, seguiste-lhe as pisadas, essa merda da política. 
- Não acredito que esteja a usar essa linguagem, mãe.

- Merda é pouco filho. Merda é pouco. É por isso que, por mais que nos lavemos, não há água que chegue para nos limparmos do passado. (COUTO, 2004, p.70)

O passado de violência contra os nativos é um verdadeiro pesadelo para o colonizador no momento da descolonização, trazendo o medo da revanche do colonizado que viveu a vida inteira sob o jugo do poder colonial. A mãe de Lourenço tem consciência disso, ao contrário do filho que pensa ainda estar revestido da autoridade colonial num momento em que ela já não existe mais. Sem conseguir convencer o filho, a mãe foge para a África do Sul com a ajuda da negra Jessumina:

Lourenço é acordado por Andaré. Pensa: agora é que ele me vem matar. Por debaixo da almofada retira a faca-de-mato. Mas não. $\mathrm{O}$ outro se explica e desfaz o equívoco: o cego simplesmente é portador de uma mensagem de Jessumina. Ela levou dona Margarida pelo rio, foram para Pebane. De lá é mais fácil sair de Moçambique. Dizem: os brancos de lá estão fugindo para a África do Sul. Lourenço de Castro se alivia - a mãe. (COUTO, 2004, p.93)

Em O esplendor de Portugal (1999), em meio ao caos que o território angolano se transformou, colonos portugueses tentam desesperadamente embarcar para Portugal, deixando para trás as suas propriedades e todos os seus pertences: terrenos, colheitas, automóveis, geladeiras, fogões, etc. É a luta desesperada para escapar do inferno que o paraíso colonial se transformou:

...das toalhinhas de papel que se esqueceram de levar consigo para Malanje ou Salazar ou Luanda, aguardando no aeroporto e no cais semanas e semanas, estendidos em cobertores, mantas, trouxas, por um avião ou um barco impossíveis, traficando entre nós, de papel e lápis na mão em negociações ridículas, moradias, propriedades, automóveis que não havia já, oferecendo a colheita inteira ou os terrenos que possuímos no Cuito por um lugar no porão, enquanto nas suas costas os milícias lhes roubavam sem vergonha os cobertores, as mantas, as trouxas. (ANTUNES, 1999, p.247)

Os colonos que deixavam Angola embarcavam para um futuro incerto em Portugal, em razão de décadas de convivência africana. Nesse sentido, vale lembrar a reflexão de um dos personagens-narradores (Isilda) de $O$ esplendor de Portugal: “...para chegarmos a Lisboa onde não nos aceitam" (ANTUNES, 1999, 244). Outro exemplo do 
preconceito sofrido pelos retornados a Portugal pode ser observado no regresso do médico (soldado), narrador de Os cus de Judas (2003):

\begin{abstract}
- Vocês vêm de Angola convencidos que são uns grandes homens mas isto aqui não é o mato, seu tropa -...

$\mathrm{O}$ burocrata idoso que seguia à minha frente voltou-se para trás assarapantado, uma senhora disse para outra Chegam todos assim lá de África, coitadinhos, e eu senti que me olhavam como se olham os aleijados que rastejam de muletas nas cercanias do Hospital Militar, sapos coxos fabricados pela estupidez do Estado Novo, que ao fim da tarde, no Verão, escondiam os cotos envergonhados nas mangas das camisolas, pombos doentes pousados nos bancos do jardim da Estrela, ou misturando-se com as prostitutas que na Rua Artilharia roçam as ancas ossudas pelos Mercedes a diesel de construtores civis de fósforo nos dentes, a suarem de cio sob os chapéus tiroleses. (ANTUNES, 2003, p.100)
\end{abstract}

O caráter conflituoso e não pacífico da descolonização, carregado de medo, insegurança e violência, que quase sempre provoca o retorno dos colonos aos países colonizadores é explicado por Frantz Fanon (1979) e Albert Memmi (1967).

Para Fanon (1979, p.25), a descolonização é sempre um fenômeno violento, substituindo, sem transição, completa e absolutamente, uma espécie de homens por outra espécie de homens, e é também um programa de desordem absoluta, quando se propõe a mudar a ordem do mundo.

A descolonização, sabemo-lo, é um processo histórico, isto é, não pode ser compreendida, não encontra a sua inteligibilidade, não se torna transparente para si mesma senão na exata medida em que se faz discernível o movimento historicizante que lhe dá forma e conteúdo. A descolonização é o encontro de duas forças congenitamente antagônicas que extraem sua originalidade precisamente dessa espécie de substantificação que segrega e alimenta a situação colonial. (FANON, 1979, p.26)

E para Albert Memmi (1967, p.3), a descolonização é um processo lento, difícil e doloroso, comparável à convalescença de uma longa e grave enfermidade.

Verifica-se, em definitivo, que o colonizador é uma doença do europeu, da qual deve ser completamente curado e preservado. E certamente há um drama do colonizador, que seria absurdo e injusto subestimar. Pois sua cura supõe uma terapêutica difícil e dolorosa, um desenraizamento e uma reforma de suas condições atuais de existência. (MEMMI, 1967, p.123) 
Dessa forma, o que se assiste em Angola e Moçambique, com a tomada do poder e do controle territorial pelos grupos de revolucionários angolanos e moçambicanos, é um quadro de desordem absoluta que inverte a ordem política das colônias. Vejamos como a colona Isilda, de $O$ esplendor de Portugal, vê a cidade de Luanda depois da independência angolana:

Não pode ser Luanda porque nunca estive aqui, uma cidade de indígenas construída por indígenas, ruínas amontoadas, pedaços de igreja, trastes na rua, lixo. /..../ uma cidade a imitar outra cidade como os africanos os imitam os gestos e a roupa, esboços de moradias, esboços de jardins, praças ridículas, prédios que se esqueceram de completar, escadas que não conduzem a nada, um duende de gesso num quintal que não há, uma cidade a que chamam Luanda. (ANTUNES, 1999, p. 342)

Esse cenário de transformação que desconfigura o mundo colonial, visto com tristeza e desalento pelo colono português, é visto com euforia pelas personagens africanas. Observemos pela voz da estátua Yaka a alegria que se espalha pelo território angolano no momento em que se tem certeza da independência:

... um dia estourou, explodiu,floresceu aquela música MPLA Weya, MPLA chegou, e mais as palavras que agora eram música, Owini oku soma, o Povo no poder, e aquela música entrou nas casas baixas da Camunda, se infiltrou nos bananais Cavaco, subiu com o rio para o interior, se separou em afluentes para o Dombe Grande, as Mundas, Caitou, e outro afluente para o Huambo e Bie pela e outro pelo Lobito e o Pundo para o Cuanza-Sul Catumbela e nas grutas úmidas se dançava e nos platôs secos se dançava e reconheci nela a canção da minha criação.... (PEPETELA, 1984, p.248)

Vejamos também como é narrada em Vinte zinco a cena em que os presos políticos da PIDE ganham a liberdade:

De repente, lhe chega aos ouvidos a algazarra de gente correndo. $\mathrm{O}$ clamor e a vozeria chegam no mesmo caminho, mas em oposta direcção. E começam a passar por ele homens correndo, cantando e gritando. São os presos que escapam da cadeia. (COUTO, 2004, p.100)

No fim do romance de Mia Couto, a morte de Lourenço de Castro e as pinceladas de tinta branca de Andaré Tchuvisco, que dissolvem as paredes da prisão, 
são ações metafóricas que representam a dissolução do poder colonial e seus sistemas de tortura.

\section{Considerações finais}

Conforme podemos observar nas obras analisadas, concordando com Fanon e Memmi, a descolonização é realmente um processo difícil, doloroso e violento. $\mathrm{O}$ passado de violência do colonizador contra o colonizado, durante a ocupação colonial, desencadeia uma ação violenta também por parte do colonizado no momento da descolonização. São as duas faces do colonialismo.

Dessa forma, Yaka (1984) apresenta uma história de opressão e violência contra o colonizado em quase todas as suas partes, mostrando que o colonizador enriquece e toma conta das terras angolanas, e na última parte apresentando a redenção do colonizado, quando retrata o período da descolonização. Em Vinte zinco (2004), Mia Couto, embora abordando um tempo cronológico extremamente curto (apenas 12 dias, compensados com flashes do passado) se comparado ao abordado por Pepetela em Yaka, faz praticamente o mesmo que o escritor angolano. Ambos fazem um jogo metonímico de causa e efeito. Quase todos os colonos que se põem em fuga, ou são mortos pelos nativos, têm um passado manchado de sangue ou abusos contra os colonizados. Exemplos disso são Xandinho e Bartolomeu Espinha em Yaka, que massacraram muitos nativos em prol da ganância colonial, e Lourenço de Castro, o agente das mãos sujas de sangue, de Vinte e zinco, uma sinédoque da repressão e da tortura do regime do Estado Novo português.

Já nos romances de António Lobo Antunes há duas visões diferentes: a do colono explorador que não abre mão dos direitos que ele julga adquiridos sobre a terra alheia e insiste em lutar por ela até o fim, caso da família de colonos de $O$ esplendor de Portugal; e o do soldado português que se vê obrigado a embarcar para uma guerra que não é sua e por isso não poupa o governo português de pesadas críticas. Nesse segundo caso há uma clara consciência de que aquela terra "não lhe pertence", enquanto no primeiro, ocorre o contrário.

Como iniciamos o artigo falando da chuva para abordar a representação literária do processo de descolonização em Angola e Moçambique em romances de escritores angolanos, moçambicanos e portugueses, encerramos também com ela, reafirmando que 
nos romances analisados a chuva representa "alegria e vida" para os africanos, enquanto que para os portugueses ela representa "tristeza e morte".

\section{Referências Bibliográficas:}

ABDALA JÚNIOR, Benjamin. De vôos e ilhas: literatura e comunitarismos. Cotia: Ateliê Editorial, 2003.

ANTUNES, António Lobo. O esplendor de Portugal. Rio de Janeiro: Rocco, 1999

$$
\text { Os cus de Judas. Rio de Janeiro: Objetiva, } 2003 .
$$

CANDIDO, Antonio. Literatura e sociedade. 8 ed. São Paulo: T. A. Queiroz, 2000.

COUTO, Mia. Vinte e zinco. 2 ed. Lisboa: Editorial Caminho, 2004.

FANON, Frantz. Os condenados da Terra. 2 ed. Trad. José Laurênio de Melo. Rio de Janeiro: Civilização Brasileira, 1979.

LOURENÇO, Eduardo. O labirinto da saudade: psicanálise mítica do destino português. Lisboa: Gradiva, 2004.

MEMMI, Albert. Retrato do colonizado precedido pelo retrato do colonizador. Trad. Roland Corbisier e Mariza Pinto Coelho. Rio de Janeiro: Paz e Terra, 1967.

NETO, Agostinho. Sagrada esperança. São Paulo: Ática, 1984.

PEPETELA. Yaka. São Paulo: Ática, 1984. 